\title{
Battery Equalization Control Based on the Shunt Transistor Method
}

\author{
Javier Gallardo-Lozano (PhD student, University of Extremadura - UE), Enrique Romero-Cadaval (Professor, UE), \\ María Isabel Milanés-Montero (Professor, UE), Miguel A. Guerrero-Martinez (Researcher, UE)
}

\begin{abstract}
Electric Vehicle (EV) researches are currently becoming of special importance and the $\mathrm{EV}$ battery system is particularly relevant in the EV design. In these applications, series connected batteries are necessary since a single battery cannot achieve the voltage requirements. Internal and external sources lead the batteries string to become unbalanced, which is an important factor to be taken into account, as premature cells degradation, safety hazards, and reduced capacity will occur for unbalanced systems. The different balancing methods are presented and compared in this paper, and finally the switch capacitor and the double-tiered switching capacitor are considered the best option. However, their speed depends on the voltage difference between the batteries in the string, and when their voltage difference is low, the equalization speed decreases significantly, leading the battery pack to be unbalanced for longer. A novel equalization method is presented, that improves the aforementioned methods performance by applying a new control to a shunt transistor method. Low cost, size, and complexity, together with higher speed and efficiency are obtained. A prototype has been built, and experimental results are presented.
\end{abstract}

Keywords - Batteries; Battery Management Systems; Battery chargers.

\section{INTRODUCTION}

Nowadays, a large part of the vehicles research is being focused on EVs (Electric Vehicles) because of many reasons such as environmental awareness (which leads to autoemission standards getting stricter to follow, more efficient vehicles, Government encouragements, etc.), continuous increase of the oil price due to the natural resource exhaustion and the worrying instability in the Middle East, etc.

Hybrid Electric Vehicles (HEVs) were the first step to the trend toward the Electric Vehicles [1], and BEVs (Battery Electric Vehicles) are currently coming out more and more [2].

There is a great variety of different battery technologies, which have been analyzed and applied to the EVs, but new researches are developing the Lithium-based batteries which are consolidated as the most viable option for energy storage applications, especially for EVs [3]-[5].

Most of applications with energy storage are designed with a battery voltage higher than that which can be obtained from a single electrochemical battery, and therefore series strings of cells (each battery that makes up the whole battery pack is called cell hereafter unless otherwise noted) are used to meet voltage requirements such as in EVs [6]-[8].

Because of the cells string configuration, cells imbalance in battery systems is a problem to deal with and an important matter in the battery system life [9]. A battery system without a balancing technique can lead its cells to be overcharged, undercharged, or even overdischarged, and it takes special importance in Li-ion cells [10]-[12].

Imbalance harms performance can be classified in four different groups [13]. The first group deals with premature cells degradation because of the overvoltage exposure. The second group is safety hazards from overcharged cells. The third group is based on the early charge termination resulting in reduced capacity, and finally, the forth group deals with the early discharge termination. This imbalance is caused by two major categories [14]-[15], they are the internal sources that consist of manufacturing variance in physical volume, internal impedance variations and self-discharge rate differences; and external sources such as thermal difference across the battery pack.

Many different balancing methods can be found in [16][19]. According to [16], balancing methods can be classified into three main groups, as shown in Fig. 1: Battery Selection, Passive Balancing methods, and Active Balancing ones. Battery Selection methods deal with designing the battery pack by selecting the cells with similar properties. These methods are not enough to keep the series string balanced since the cells self-discharge can vary differently along their lifetime. It can be useful in the case of complementing a balancing system.

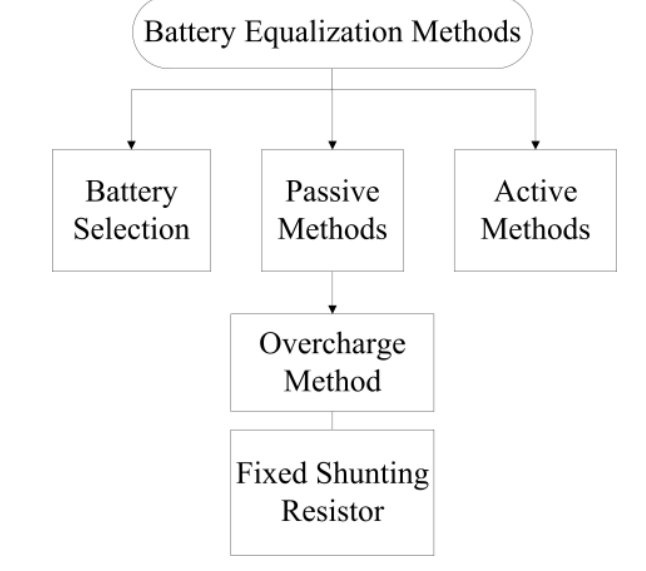

Fig. 1. Classification of the battery equalization methods.

In Passive equalization no active control is used to balance. Only Lead-acid and Nickel-based batteries can be used as Libased batteries cannot be overcharged. At high SOC (Battery State-of-Charge), the charge process for lead-acid and nickelbased cells becomes inefficient since its water begins to dissociate and energy goes into electrolysis rather than the 
charge process. However, Li-based cells do not have the aqueous component, and so do not have the gassing overcharge process that allows a passive equalization in other chemistries. Since the Li-based battery is the most important one, according to these previous lines, this paper is focused on active balancing methods, which use external circuits to actively transport the energy among cells in order to balance them.

Fig. 2 shows the classification of the different active balancing methods [16].

In Cell Bypass methods, cells currents are bypassed when the cells voltages reach their upper limit. Cell to cell methods transfer the extra energy stored in the most charged cells to the adjacent least charged ones. Cell to pack methods transfer the energy from the highest voltage cell to the whole battery pack, pack to cell methods transfer the energy from the whole battery pack to a single cell, by means of galvanic isolated DC/DC converters, and finally, cell to pack to cell methods transfer the energy from the set cell(s) to the whole pack, from the whole pack to the target cell(s) or from the set cell(s) to the target cell(s).

The different active methods are summarized and compared in Table I [16], where * is every analyzed method which is defined by its section number in [16] and follows the same order than shown in Fig. 2.

Parameters of comparison:

T. Balancing nature: ST (Shunting), SL (Shuttling), EC (Energy Conversion).

Components. S (Switches), R (Resistors), L (Inductors), C (Capacitors), D (Diodes).

P1. Cost (1: expensive, 3 : cheap)

P2. Efficiency (1: low, 3: high).

P3. Application (1: only allows low power, 3: allows high power).

P4. Charge/Discharge type (1: unidirectional, 3: bidirectional).

P5. Best effective period (1: one effective mode, 3: both modes are effective)

P6. Speed (1: high, 3: low).

P7. Implementation (1 low, 3: high).

P8. Complexity (1: high, 3: low).

P9. Size (1: big, 3: small).

P10. Modular (1: difficult, 3: easy).

P11. Switch Voltage Stress (1: high, 3: low).

P12. Switch Current Stress (1: high, 3: low).

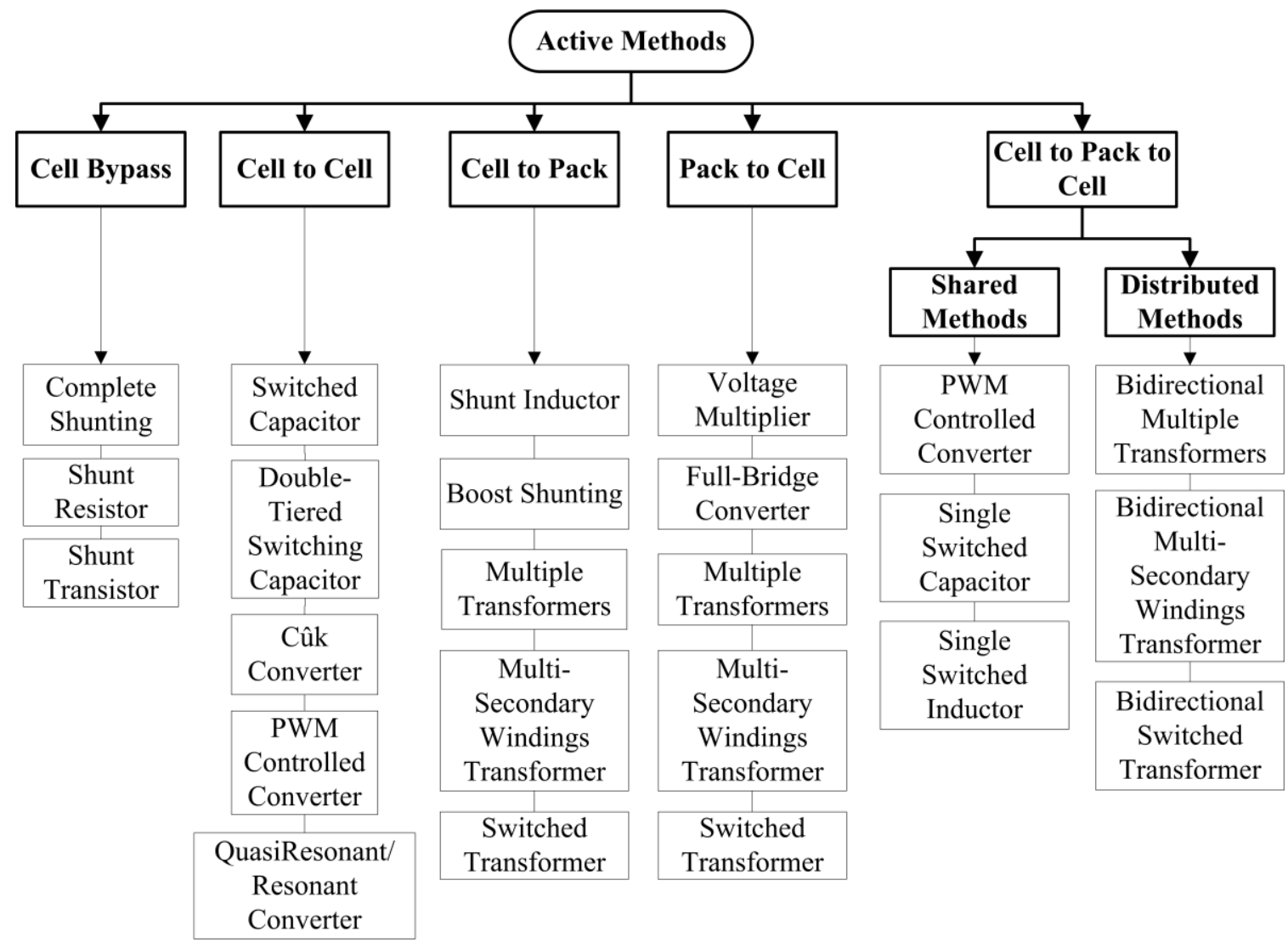

Fig. 2. Classification of the different active balancing methods. 
TABLE I

Classification OF ACTIVE BALANCING Methods

\begin{tabular}{|c|c|c|c|c|c|c|c|c|c|c|c|c|c|c|c|c|c|c|c|}
\hline \multirow[t]{2}{*}{$*$} & \multirow[t]{2}{*}{$\mathrm{T}$} & \multicolumn{5}{|c|}{ Components } & \multirow[t]{2}{*}{ P1 } & \multirow[t]{2}{*}{ P2 } & \multirow[t]{2}{*}{ P3 } & \multirow[t]{2}{*}{ P4 } & \multirow[t]{2}{*}{ P5 } & \multirow[t]{2}{*}{ P6 } & \multirow[t]{2}{*}{ P7 } & \multirow[t]{2}{*}{ P8 } & \multirow[t]{2}{*}{ P9 } & \multirow[t]{2}{*}{ P10 } & \multirow[t]{2}{*}{ P11 } & \multirow[t]{2}{*}{ P12 } & \multirow[t]{2}{*}{ Total } \\
\hline & & SW & $\mathrm{R}$ & $\mathrm{L}$ & $\mathrm{C}$ & $\mathrm{D}$ & & & & & & & & & & & & & \\
\hline 3.1 .1 & ST & $4 n$ & & & & & 3 & 3 & 1 & 3 & 3 & 3 & 2 & 3 & 3 & 3 & 3 & 1 & 2.58 \\
\hline 3.1 .2 & ST & $\mathrm{n}$ & $\mathrm{n}$ & & & & 3 & 1 & 1 & 1 & 1 & 3 & 1 & 3 & 2 & 3 & 3 & 1 & 1.92 \\
\hline 3.1 .3 & ST & $\mathrm{n}$ & & & & & 3 & 1 & 1 & 1 & 1 & 3 & 2 & 3 & 3 & 3 & 3 & 1 & 2.08 \\
\hline 3.2 .1 & SL & $2 n$ & & & $\mathrm{n}-1$ & & 3 & 3 & 3 & 3 & 3 & 1 & 2 & 3 & 2 & 3 & 3 & 1 & 2.50 \\
\hline 3.2 .2 & SL & $2 n$ & & & $2 n-3$ & & 2 & 3 & 3 & 3 & 3 & 2 & 2 & 3 & 2 & 3 & 3 & 1 & 2.50 \\
\hline 3.2 .3 & SL & $2(n-1)$ & & $\mathrm{n}$ & $\mathrm{n}-1$ & & 2 & 2 & 3 & 3 & 1 & 2 & 2 & 1 & 2 & 3 & 3 & 3 & 2.17 \\
\hline 3.2 .4 & SL & $2(n-1)$ & & $\mathrm{n}-1$ & & & 2 & 2 & 3 & 3 & 1 & 2 & 2 & 1 & 2 & 3 & 3 & 3 & 2.17 \\
\hline 3.2 .5 & SL & $2(n-1)$ & & $2(n-1)$ & $\mathrm{n}-1$ & & 1 & 2 & 3 & 3 & 1 & 2 & 2 & 1 & 1 & 3 & 3 & 3 & 2.00 \\
\hline 3.3 .1 & SL & $2(n+1)$ & & 1 & & 1 & 2 & 2 & 3 & 3 & 1 & 1 & 2 & 1 & 3 & 2 & 2 & 3 & 1.92 \\
\hline 3.3 .2 & EC & $\mathrm{n}+1$ & & $n+1$ & 1 & $n+1$ & 2 & 2 & 3 & 3 & 1 & 2 & 2 & 1 & 2 & 3 & 3 & 3 & 2.17 \\
\hline 3.3 .3 & EC & $\mathrm{n}$ & & $2 n$ & & $\mathrm{n}$ & 1 & 1 & 3 & 3 & 1 & 2 & 2 & 1 & 1 & 2 & 2 & 2 & 1.83 \\
\hline 3.3.4 & $\mathrm{EC}$ & $\mathrm{n}$ & & $\mathrm{n}+1$ & & 1 & 1 & 1 & 3 & 3 & 1 & 1 & 2 & 1 & 1 & 2 & 2 & 3 & 1.67 \\
\hline 3.3 .5 & EC & $2 n$ & & 2 & & $2 n+1$ & 1 & 1 & 3 & 3 & 1 & 1 & 2 & 1 & 1 & 2 & 2 & 3 & 1.75 \\
\hline 3.4 .1 & SL & 1 & & & $\mathrm{n}$ & $2 \mathrm{n}$ & 3 & 3 & 3 & 1 & 1 & 2 & 2 & 3 & 2 & 1 & 1 & 2 & 2.17 \\
\hline 3.4 .2 & $\mathrm{EC}$ & $4 n$ & & & & & 1 & 3 & 3 & 3 & 1 & 3 & 2 & 2 & 2 & 3 & 3 & 3 & 2.42 \\
\hline 3.4 .3 & EC & 1 & & $2 n$ & & $\mathrm{n}$ & 1 & 1 & 3 & 1 & 1 & 2 & 2 & 3 & 1 & 2 & 2 & 2 & 1.83 \\
\hline 3.4 .4 & $\mathrm{EC}$ & 1 & & $\mathrm{n}+1$ & & $\mathrm{n}$ & 1 & 1 & 3 & 1 & 1 & 2 & 2 & 3 & 1 & 2 & 2 & 3 & 1.75 \\
\hline 3.4 .5 & $\mathrm{EC}$ & $2 n+1$ & & 2 & 1 & 1 & 1 & 1 & 3 & 1 & 1 & 1 & 2 & 1 & 1 & 2 & 2 & 3 & 1.67 \\
\hline \begin{tabular}{|l|}
3.5 .1 \\
\end{tabular} & $\mathrm{EC}$ & $2(n-1)$ & & $\mathrm{n}-1$ & 1 & & 1 & 2 & 3 & 3 & 1 & 2 & 2 & 1 & 2 & 2 & 2 & 2 & 2.00 \\
\hline 3.5 .2 & SL & $4 n$ & & & & & 3 & 3 & 3 & 3 & 3 & 1 & 2 & 1 & 3 & 3 & 3 & 2 & 2.33 \\
\hline 3.5 .3 & SL & $4 n$ & & 1 & & & 2 & 2 & 3 & 3 & 3 & 1 & 2 & 1 & 3 & 3 & 3 & 2 & 2.17 \\
\hline \begin{tabular}{|l|}
3.5 .4 \\
\end{tabular} & $\mathrm{EC}$ & $2 n$ & & $2 n$ & & & 1 & 1 & 3 & 3 & 1 & 2 & 2 & 1 & 1 & 2 & 2 & 2 & 1.83 \\
\hline 3.5 .5 & $\mathrm{EC}$ & $\mathrm{n}+1$ & & $\mathrm{n}+1$ & & & 1 & 1 & 3 & 3 & 1 & 2 & 2 & 1 & 1 & 2 & 2 & 3 & 1.75 \\
\hline 3.5 .6 & $\mathrm{EC}$ & $4 n+1$ & & 2 & & & 1 & 1 & 3 & 3 & 1 & 2 & 2 & 1 & 1 & 2 & 2 & 3 & 1.83 \\
\hline
\end{tabular}

The total average in Table I has been calculated by using the same weight for each parameter and as it can be presented, the switch capacitor and the double-tiered switching capacitor are the ones with the highest average value.

In the switch capacitor method [16], two states are alternated continuously: in the first state, each capacitor is set in parallel with its corresponding upper cell, and therefore, the capacitor is set to the cell voltage $\left(V_{u, i}\right)$, delivering or demanding energy from the mentioned cell. In the second state, the capacitors are set in parallel with their corresponding lower cell, transferring or demanding energy from this one in order to reach this new voltage $\left(V_{l, i}\right)$. After cycles of this process, both cells will be balanced. The topology is depicted in Fig. 3.

Each switching cycle, the $i^{\text {th }}$-capacitor $\left(C_{i}\right)$ transfers the current $\left(I_{c, i}\right)$ from the most charged adjacent cell to the least charged adjacent cell according to

$$
I_{c, i}=C_{i} \quad\left(V_{u, i}-V_{l, i}\right) f_{s w} .
$$

where $f_{s w}$ is the switching frequency.

The double-tiered switching capacitor method is a derivation of the switched capacitor one, the difference is that it uses two capacitor tiers for shuttling energy, and the equalization time is reduced even to a quarter [16]. Its topology is presented in Fig. 4.

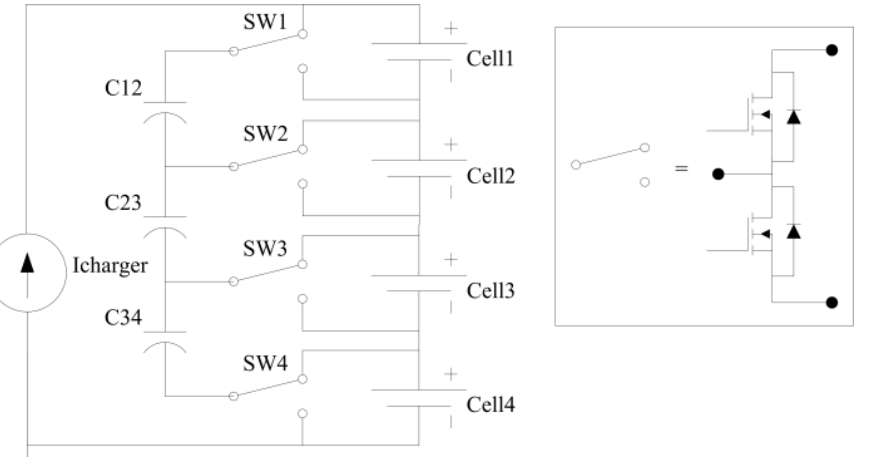

Fig. 3. Switch Capacitor method.

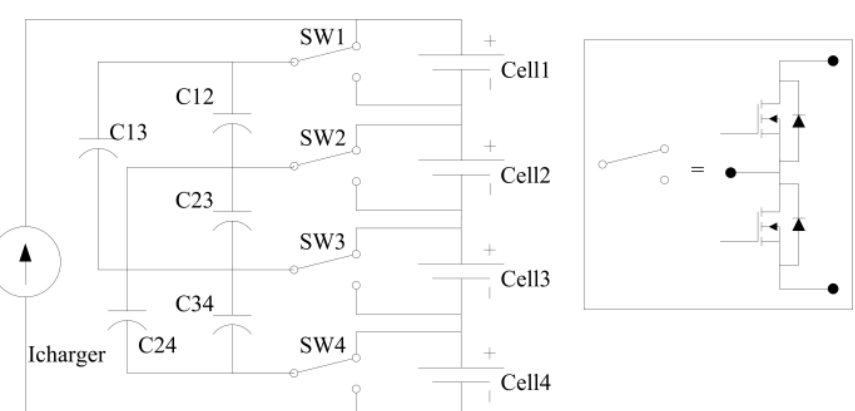

Fig. 4. Double-Tiered Switching Capacitor method. 
Based on (1), the equalization speed of these two methods (switch capacitor and double-tiered switching capacitor) depends on the cells voltage difference. In consequence, when the voltage difference is low, the equalization speed is very low as well, and this is probably a big disadvantage, since the different cells remain unbalanced for longer.

According to the parameters of comparison, a low cost and very simple method is proposed, presenting a novel control for a Cell bypass balancing method in a generic battery charging process. The equalization current, and therefore the equalization speed, is high.

In Section II the proposed equalization system is presented and in Section III and Section IV the different simulation and experimental results are shown, respectively, validating this proposed balancing method. Finally, Section V remarks the different conclusions.

\section{EQUALIZATION SYSTEM DESIGN}

In this paper a new control for a shunt transistor (cell bypass) equalization is presented. This method is based on a MOSFET working in saturation mode as a variable resistance, instead of using a resistance, whose value is fixed. The goal of this new control is to manage the amount of current that passes through each cell that makes up the battery pack, in order to balance the whole battery system. This control allows easy implementation and low complexity, it is easy to modularize and the efficiency is improved in comparison with the conventional control methods since the bypassed current through the MOSFET decreases when its corresponding cell is being closer to be balanced or even it stops being bypassed under some conditions.

The bypassed current through the MOSFET is regulated varying its gate-source voltage. The higher the gate-source voltage of the MOSFET is, the higher the bypassed current through the MOSFET is, and therefore the less the corresponding cell is charged, and vice versa.

In order to be able to equalize during the charging/driving process or during the regenerative braking, a MOSFET is set in parallel to each cell of the string in the battery pack. The MOSFET is an n-channel device.

The voltage of every cell that makes up the battery is measured, and their average voltage is calculated and considered the reference.

The difference between every cell voltage and the cells average value is extracted.

When battery charging mode or regenerative braking during driving (discharging mode is opposite), cells with lower voltage than the average one need to be charged as much as possible in order to reach the average value as soon as they can. All the current that comes to the battery from the charger passes through these cells, and therefore their corresponding MOSFETs are set to the off-state and do not bypass the cells.

On the other hand, cells with higher voltage than the average one are charged in a lower rate of current, bypassing the remaining current. The closer to the average value their voltage is, the lower the amount of current is bypassed by their corresponding MOSFET. Once the cell voltage reaches the reference, its MOSFET is set to the off-state and all the current coming to the battery goes through the cell. The opposite process occurs during discharging. It allows the system to decrease the energy losses.

The aforementioned process of equalizing under the charge or regenerative braking during driving conditions is depicted in [20], but in our case the equalization method establishes a maximum for the MOSFET equalization current, $I_{M \text {, max }}$ (green solid line in Fig. 5), in order to keep the losses under a limit.

The lower the difference is, the lower the bypassed current is, the less the equalization is being carried out, and the lower the equalization speed is. This problem increases the energy losses, and in consequence decreases the efficiency.

Something similar happens in the switch capacitor and the double-tiered switching capacitor methods (whose equalization current depends on the voltage difference between cells).

In order to avoid this problem, this proposed balancing method adds a minimum level of the bypassed current through the MOSFET, $I_{M \text {, min }}$, and the difference between the cell voltage and the reference (diff), as shown in Fig. 5. When an unbalanced cell starts the equalization process from a high difference, the control is kept according to Fig. 5 (red dotted line), but when the difference reaches the mentioned minimum level, from that moment this difference is considered fixed (although it really keeps decreasing), and so the bypassed current is fixed into a minimum value (blue solid line in Fig. 5) that allows the cell voltage to get zero error (zero difference between the cell voltage and the reference).

Once the cell voltage comes to zero error, and its corresponding MOSFET is set to off-state (the cell equalization process is stopped). Considering that there can be manufacturing and thermal variances between cells, its voltage could be oscillating around the reference, what could cause the activation and deactivation of the equalization process, and a considerable increase in the energy losses. This issue is solved by using the aforementioned minimum difference level: when the cell voltage gets the zero error, the equalization process is deactivated. In case the difference increases again, the equalization process is activated when the minimum level is reached. This idea avoids energy losses that can decrease the efficiency of the system.

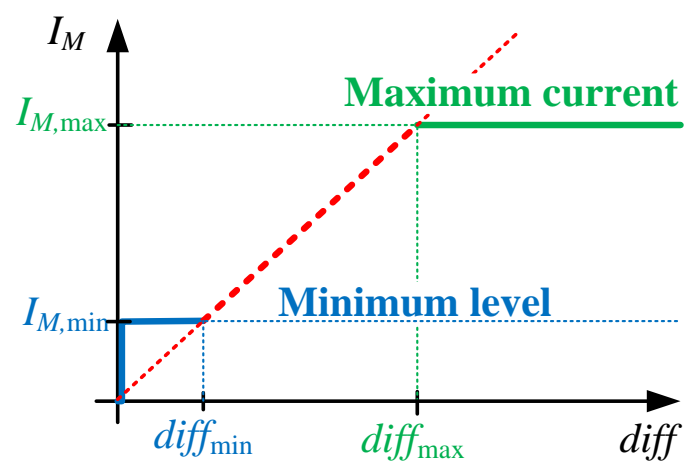

Fig. 5. Linear relation between the MOSFET current and the difference between the cell voltage and its reference. 
By increasing the minimum level, the equalization speed can be increased as well, although it means that the losses increase too. The tradeoff can be adjusted depending on the application.

The algorithm that decides whether the n-channel MOSFETs are activated or deactivated, and the algorithm and the mathematical foundation that explain how the gate-source MOSFET voltage is calculated are presented in [20], and lead to the equation of the amount of current that is bypassed for the $i^{\text {th }}$-cell, which follows $I$

$$
V_{G S i}=\sqrt{\frac{2 I_{b a t, \max }}{\operatorname{diff}_{\max } K\left(1+\lambda V_{c e l l, i}\right)} \operatorname{diff}_{i}}+V_{T i} .
$$

where $V_{G S i}$ is the MOSFET gate-source voltage, $I_{b a t \text {, max }}$ is the current received from the battery charger, $K$ is the MOSFET conduction parameter, $\lambda$ is the MOSFET lambda parameter, $V_{T}$ is the MOSFET threshold voltage, $V_{\text {cell, } i}$ is the $i^{\text {th }}$-cell (drainsource) voltage, diff $i$ is the difference between the $i^{\text {th }}$-cell voltage and the reference, and diff $f_{\max }$ is the maximum difference established in the control. In case the voltage difference is higher than diff $f_{\max }$, all of the current is bypassed through the corresponding MOSFET.

When the difference is equal or lower than diff $f_{\max }$, the current is partially bypassed through the MOSFET, and the difference keeps decreasing, until the error is zero that is when all of the current must go through the cell, and so the MOSFET is set to its off-state.

This method is only applicable to small currents. The idea of this equalization control is to avoid high unbalance that could lead to high currents. This control allows the system to balance during both charging and driving modes, as the amount of current through the cells and the MOSFETS are controlled (linear mode). It allows the system to be controlled all the time and not only at the end of the charging mode. This way, the control never allows the system to be highly unbalanced, small currents could be enough to keep the system under control. In case a new cell has to be inserted in the battery pack, this cell should be fully charged and inserted into the pack when this one is also charged, avoiding unnecessary imbalance, and therefore high currents.

\section{SIMULATION RESULTS}

A charging process is simulated for an unbalanced battery pack, which is made up with 5 Li-ion cells. The modeled system consists of $5 \mathrm{Li}$-ion cells, each of them in parallel to an $n$-channel MOSFET, the equalizer control system, and finally the port of the whole system (the battery pack), which is the current that is, in this case, injected into the battery system. The cells utilized are modeled as in [21]-[22]. The $n$-MOSFETs (modeled in their saturation region) are the "IXTP $75 \mathrm{~N} 10 \mathrm{P}$ MOSFET".

The simulation has been carried out by using Matlab/Simulink.
The battery pack is charged with a constant current of $50 \mathrm{~A}$. The maximum bypassed current through the MOSFETs is established at $5 \mathrm{~A}$. By limiting this value, the efficiency is improved. The results are shown in Fig. 6.

As it can be seen in Fig. 6, the cell voltages and currents, and the bypassed current through the MOSFETs, are shown respectively from top to bottom. The first subplot shows, attending to the cell voltages, how the battery is balanced before the end of the charging process.

The second subplot represents the different cell currents. 3 of them are not bypassed, and therefore they are being injected $50 \mathrm{~A}$. Initially, the remaining cells are partially bypassed until the system is balanced. However, as third subplot shows, a maximum of $5 \mathrm{~A}$ are bypassed through the MOSFETs, and it is followed then by a linear relationship with the voltage difference (as the difference is decreasing), as explained in Fig. 5, until the $I_{M \text {,min }}$ value is reached. Once the system is balanced all of the MOSFETs are in their off-state and no current is bypassed.

\section{EXPERIMENTAL VALIDATION}

A prototype has been built based on rapid prototyping, as shown in Fig. 7.

A laptop is used as a host computer, where the algorithm to be executed is implemented by using Matlab/Simulink, based on XPC Target.

Once the implementation was tested in simulation, it is downloaded to the target computer, which is the real time target machine Speedgoat, in charge of controlling the prototype operation. The host and the target computers are connected through Ethernet by TCP/IP protocol. The utilized Speedgoat I/O modules are IO102 for reading the analog measurements (the current received from the charger, and the different MOSFETs currents and voltages), and IO301 for delivering the PWM signals, which are the $V_{G S}$ values for the different power MOSFETs.

The target machine sends the $V_{G S}$ of each MOSFET to the control board, by using a digital signal controlled with a PWM module whose voltage levels are $0 \mathrm{~V}$ and $5 \mathrm{~V}$.

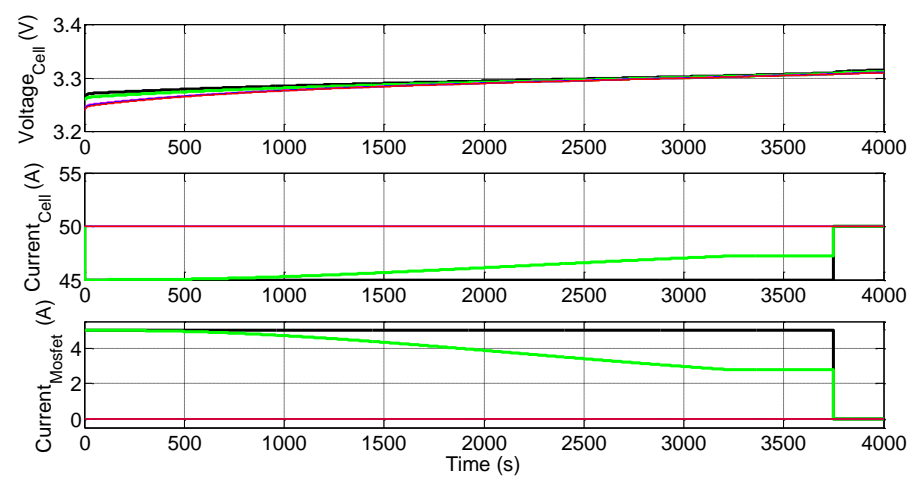

Fig. 6. From top to bottom, cell voltages (V), currents (A), and MOSFET currents (A) during a charging process. 


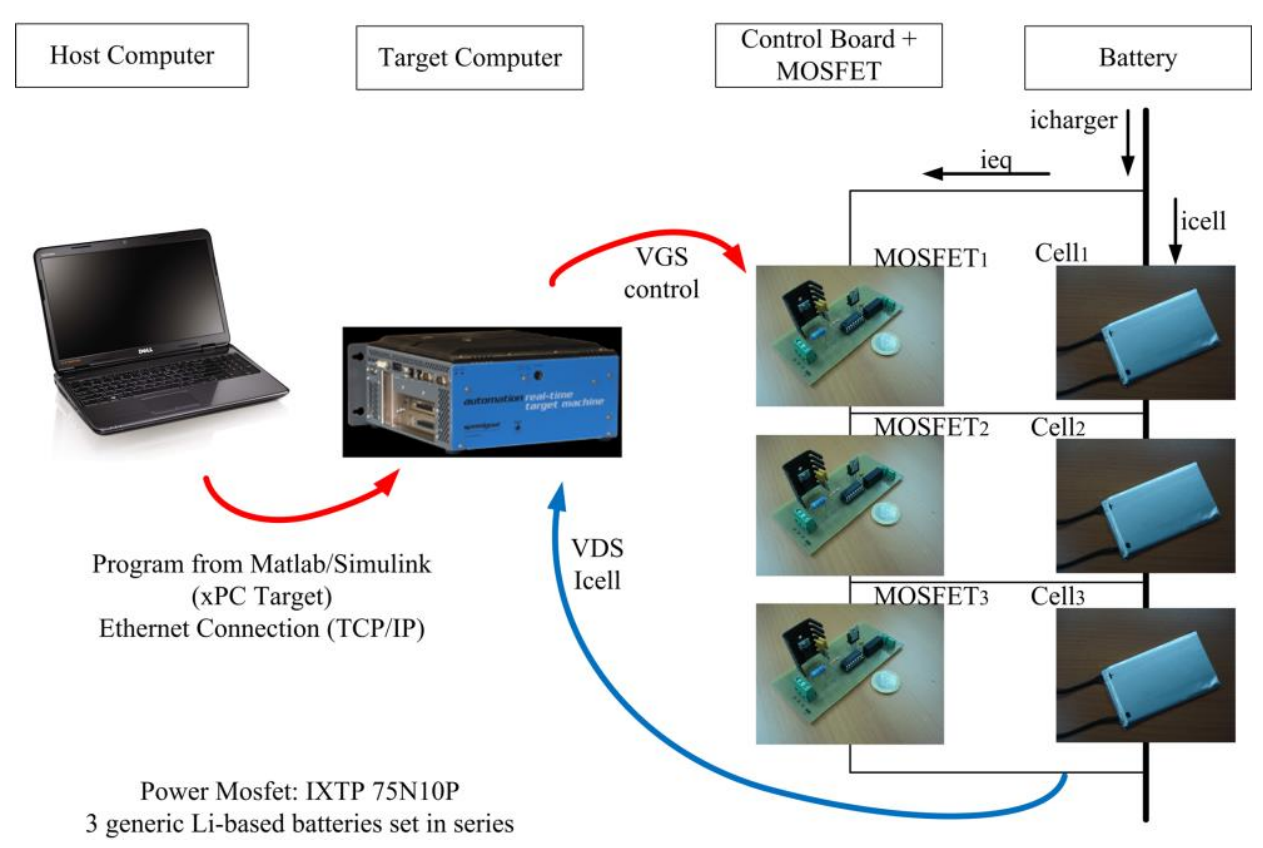

Fig. 7. Schematic of the prototype.

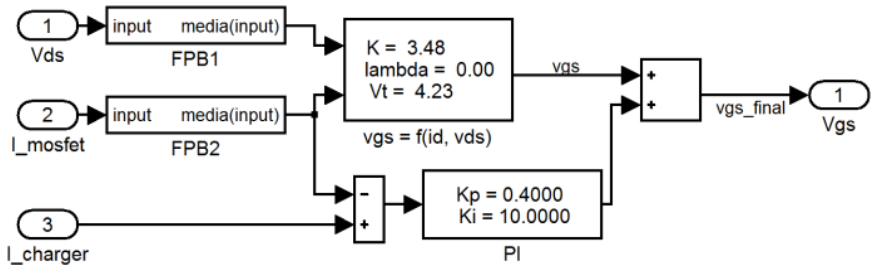

Fig. 8. PI control algorithm.

The control board allows the isolation of the received digital signal, which in turn is boosted from $5 \mathrm{~V}$ to $15 \mathrm{~V}$, in order to cover a wider range of the MOSFETs $V_{G S}$.

Finally low pass filters allow the MOSFETs to receive their corresponding constant $V_{G S}$ voltages.

Once the system is built, while the MOSFET is bypassing current its temperature increases due to its on-resistance, and it takes the MOSFET out of control. In this situation, the current increases more and more leading the device to increase its temperature more, so its current becomes even higher, closing the runaway circle.

In order to set the system under control, a feedback loop is designed, which measures the cells voltage and current. Under this control, when a MOSFET bypasses current, its temperature raises and in consequence its current raises too. So the algorithm, which includes a Proportional-Integral algorithm (adjusted by trial and error), modifies the $V_{G S}$ (it is decreased) until the current decreases to its reference. As a result, the temperature is also decreased and the current and temperature are controlled. A heating sink is mounted with the MOSFET to ensure the device correct performance.

The PI controller algorithm is depicted in Fig. 8.

With the aim of presenting how the algorithms work, Cell 1 and $\mathrm{Cell}_{2}$ voltages are measured, and $\mathrm{Cell}_{3}$ voltage is just introduced manually in the algorithm. This way, by adjusting the $\mathrm{Cell}_{3}$ voltage to different values, the system is relocated in different situations and its study is much easier.

The battery charger current is set to $2 \mathrm{~A}$.

Fig. 9 presents the measurements of the instant voltages and the corresponding MOSFETs currents for $\mathrm{Cell}_{1}$ and $\mathrm{Cell}_{2}$ along a testing time. It also presents the manually introduced instant $\mathrm{Cell}_{3}$ voltage and its theoretically calculated corresponding MOSFET current.

Attending to Fig. 9, from the initial time to $400 \mathrm{~s}$, it can be seen that $\mathrm{Cell}_{3}$ voltage is set to a lower voltage. According to the algorithm, Cell 1 and $\mathrm{Cell}_{2}$ are partially bypassed. As the Cell $l_{1}$ voltage is lower than the $\mathrm{Cell}_{2}$ one, Cell 1 bypassed current is lower too.

From $400 \mathrm{~s}$ to $450 \mathrm{~s}, \mathrm{Cell}_{3}$ voltage is set to a higher voltage. In this case, the system assumes that $\mathrm{Cell}_{1}$ and $\mathrm{Cell}_{2}$ need to be charged as much as possible, and therefore no current is bypassed, however $\mathrm{Cell}_{3}$ is partially bypassed.

From $450 \mathrm{~s}$ to $850 \mathrm{~s}, \mathrm{Cell}_{3}$ voltage is set to a lower voltage again, but the difference is lower (in comparison with the first time interval), and the bypassed current is lower. 

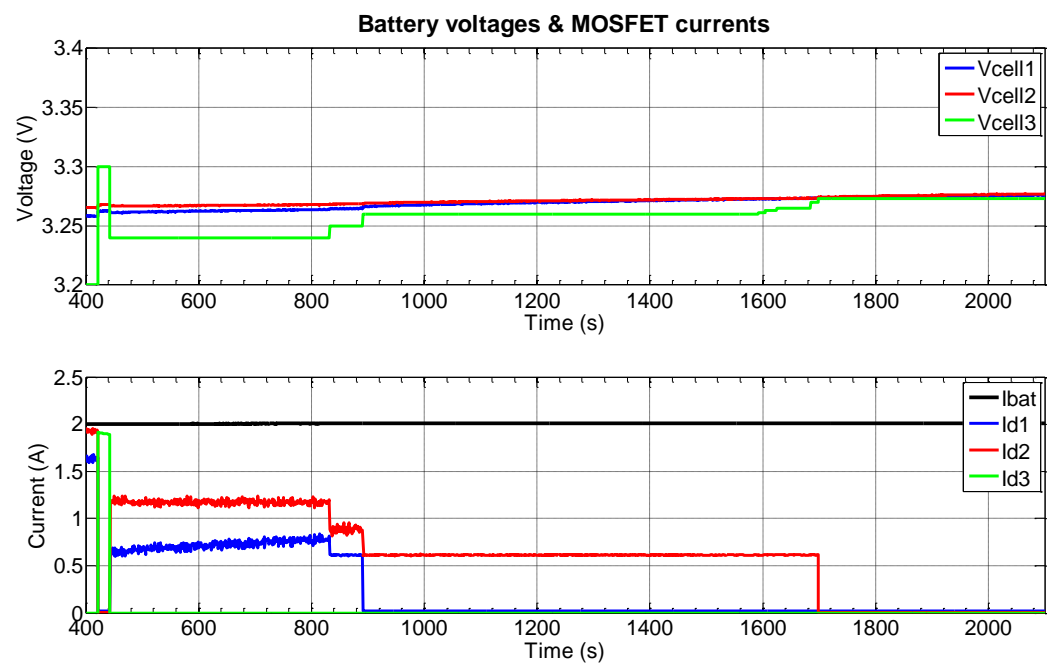

Fig. 9. Charging mode. Upper subplot, from top to bottom, instant Cell ${ }_{1}, \mathrm{Cell}_{2}$ and Cell $1_{3}$ voltages, respectively. Lower subplot, from top to bottom, instant Cell ${ }_{1}$, $\mathrm{Cell}_{2}$ and $\mathrm{Cell}_{3}$ corresponding MOSFETs currents, respectively.

From $850 \mathrm{~s}$ to $900 \mathrm{~s}$, the difference decreases, and Cell 1 enters into the aforementioned algorithm minimum level.

From $900 \mathrm{~s}$ to $1700 \mathrm{~s}$, Cell ${ }_{1}$ is balanced and therefore no current is bypassed, and $\mathrm{Cell}_{2}$ enters into the algorithm minimum level.

From $1700 \mathrm{~s}$, all the cells are balanced and from this moment the battery charge can carried out without bypassing current up to the fully charged state.

\section{CONCLUSION}

Equalization in a series string of batteries is fundamental, and takes special importance in an EV design, where the number of cells in the string is high. A well balanced battery pack assures a significant increase in its lifetime and safety, and guarantees its capacity optimization. A brief explanation of the different equalization methods, together with its comparison, has been presented. Parameters such as cost, efficiency, speed, complexity, size, or easy modularization conclude that switched capacitor and double-tiered switching capacitor methods were the best option. However, along this paper it is has been mentioned an important disadvantage of these methods: their speed depends on the voltage difference between cells, and as a result, when cells voltages are close, the equalization speed decreases significantly. It leads the battery pack to remain unbalanced for longer.

In this paper a novel equalization control for a shunt transistor (cell bypass) method is presented. This proposed active equalization system includes the different advantages of the shunt transistor method such as easy modularization, low cost and complexity (compared with other active methods [16]), and adds extra advantages such as higher speed and efficiency. The speed increase is obtained by partially bypassing the most charged cells while the EV is being driving/charging (it allows the battery system to be equalized all the time), and by adding the explained minimum bypassing level, which in turn improves the efficiency. Simulation results show that the battery can be charged/discharged at a current higher than the amount of current which can be bypassed by the MOSFETs. A prototype has been built, and experimental results prove the current management for the equalization process.

\section{ACKNOWLEDGMENT}

This work was supported by "Ministerio de Economía y Competitividad", "Comunidad Autónoma de Extremadura, Consejería de Empleo, Empresa e Innovación” (PD10067, GR10117), "Fondo Social Europeo, FEDER" and European Social Fund's Doctoral Studies and Internationalisation Programme DoRa(Archimedes Foundation).

\section{REFERENCES}

[1] P. Sveum, R. Kizilel, M. Khader and S. Al-Hallaj, "IIT Plug-in Conversion Project with the City of Chicago," Vehicle Power and Propulsion Conf. 2007. VPPC 2007. IEEE, pp. 493-497, 9-12 Sept. 2007.

[2] S. D'Arco, L. Piegari and P. Tricoli, "A modular converter with embedded battery cell balancing for electric vehicles," Electrical Systems for Aircraft, Railway and Ship Propulsion, ESARS, 2012, pp. 1-6, October 2012.

[3] M. Uno and K. Tanaka, "Influence of High-Frequency ChargeDischarge Cycling Induced by Cell Voltage Equalizers on the Life Performance of Lithium-Ion Cells," IEEE Trans. Veh. Technol., vol. 60, no. 4, pp. 1505-1515, May 2011. http://dx.doi.org/10.1109/TVT.2011.2127500

[4] B. T. Kuhn, G. E. Pitel and P. T. Krein, "Electrical properties and equalization of lithium-ion cells in automotive applications," IEEE Vehicle Power and Propulsion Conf., 2005, p. 5, 7-9 Sept. 2005.

[5] M. Broussely, M. Perelle, J. McDowall, G. Sarre and J. Martaeng, "Lithium ion: the next generation of long life batteries characteristics, life predictions, and integration into telecommunication systems," Twenty-second Int. Telecommun. Energy Conf., 2000. INTELEC, pp. 194-201, 2000. http://dx.doi.org/10.1109/INTLEC.2000.884250

[6] T. A. Stuart and Wei Zhu, "Modularized battery management for large lithium ion cells," Journal of Power Sources, vol. 196, pp. 458-464, 2011. http://dx.doi.org/10.1016/j.jpowsour.2010.04.055

[7] T. Gottwald, Z. Ye and T. Stuart, "Equalization of EV and HEV batteries with a ramp converter," IEEE Trans. Aerosp. Electron. Syst., vol. 33, no. 1, pp. 307-312, Jan. 1997. http://dx.doi.org/10.1109/7.570791

[8] N. H. Kutkut, H. L. N. Wiegman, D. M. Divan and D. W. Novotny, "Design considerations for charge equalization of an electric vehicle battery system," IEEE Trans. Ind. Appl., vol. 35, no. 1, pp. 28-35, Jan/Feb 1999. http://dx.doi.org/10.1109/28.740842

[9] Seongjun Lee and Jonghoon Kim and Jaemoon Lee and B. H. Cho, "State-of-charge and capacity estimation of lithium-ion battery using a 
new open-circuit voltage versus state-of-charge," Journal of Power Sources, vol. 185, pp. 1367-1373, 2008. http://dx.doi.org/10.1016/j.jpowsour.2008.08.103

[10] S. T. Hung, D. C. Hopkins and C. R. Mosling, "Extension of battery life via charge equalization control", IEEE Trans. Ind. Electron., vol. 40, no. 1, pp. 96-104, Feb. 1993. http://dx.doi.org/10.1109/41.184826

[11] P. T. Krein, R. S. Balog, "Life extension through charge equalization of lead-acid batteries," 24th Annu. Int. Telecommun. Energy Conf., 2002. INTELEC, pp. 516-523, 2002.

[12] D. C. Hopkins, C. R. Mosling and S. T. Hung, "Dynamic equalization during charging of serial energy storage elements," IEEE Trans. Ind. Appl., vol. 29, no. 2, pp. 363-368, Mar./Apr. 1993. http://dx.doi.org/10.1109/28.216545

[13] Y. Barsukov, "Battery Cell Balancing: What to Balance and How," 2006 Portable Power Design Seminar - Texas Instruments, 2006.

[14] Hong-Sun Park and Chol-Ho Kim and Ki-Bum Park and Gun-Woo Moon and Joong-Hui Lee, "Design of a Charge Equalizer Based on Battery Modularization", IEEE Trans. Veh. Technol., vol. 58, pp. 32163223, 2009. http://dx.doi.org/10.1109/TVT.2009.2015331

[15] W. F. Bentley, "Cell balancing considerations for lithium-ion battery systems," Twelfth Annu. Battery Conf. on Appl. and Advances, 1997 pp. 223-226, 14-17 Jan. 1997. http://dx.doi.org/10.1109/BCAA.1997.574107

[16] J. Gallardo-Lozano, E. Romero-Cadaval, M. I. Milanés-Montero and M. A. Guerrero-Martínez, "Battery Equalization Active Methods," Journal of Power Sources. ISSN 0378-7753, vol. 246, pp. 934-949. Elsevier, Jan. 2014. http://dx.doi.org/10.1016/j.jpowsour.2013.08.026

[17] Jian Cao, N. Schofield and A. Emadi, "Battery balancing methods: A comprehensive review," IEEE Vehicle Power and Propulsion Conf., 2008. VPPC '08, pp.1-6, 3-5 Sept. 2008. http://dx.doi.org/10.1109/VPPC.2008.4677669

[18] M. Daowd, N. Omar, P. Van Den Bossche and J. Van Mierlo, "Passive and active battery balancing comparison based on MATLAB simulation," IEEE Vehicle Power and Propulsion Conf., VPPC 2011 , pp. 1-7, 6-9 Sept. 2011. http://dx.doi.org/10.1109/VPPC.2011.6043010

[19] Kong Zhi-Guo, Zhu Chun-Bo, Lu Ren-Gui and Cheng Shu-Kang, "Comparison and Evaluation of Charge Equalization Technique for Series Connected Batteries," 37th IEEE Power Electronics Specialists Conf., 2006. PESC '06, pp. 1-6, 18-22 June 2006. http://dx.doi.org/10.1109/PESC.2006.1711751

[20] J. Gallardo Lozano, A. Lateef, E. Romero Cadaval and M. I. Milanés Montero, "Active Battery Balancing for Electric Vehicles Battery Pack," Scientific Journal of Riga Technical University. Electrical, Control and Communication Engineering. vol. 2/2013, ISSN 2255-9140, pp. 40-46. Riga Technical University. Riga, Latvia, June 2013.

[21] J. Gallardo-Lozano, M. I. Milanes-Montero, M. A. Guerrero-Martinez and E. Romero-Cadaval, "Three-phase bidirectional battery charger for smart electric vehicles," 7th Int. Conference-Workshop Compatibility and Power Electronics, CPE 2011, pp.371-376, 1-3 June 2011 http://dx.doi.org/10.1109/CPE.2011.5942263

[22] J. Gallardo Lozano, M. I. Milanés Montero, M. A. Guerrero Martínez and E. Romero Cadaval, "Electric Vehicle Battery Charger for Smart Grids," Electric Power Systems Research, vol. 90, pp. 18-29, ISSN 0378-7796. Elsevier, Sept. 2012.

http://dx.doi.org/10.1016/j.epsr.2012.03.015

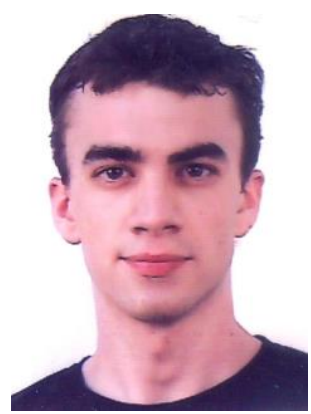

Javier Gallardo-Lozano was born in Badajoz, Spain, in 1968. He received the B. Sc. and the M. Sc. degrees electronic engineering at University of Extremadura, Spain, in 2007 and 2009, respectively, where he is currently working toward the $\mathrm{Ph}$. D. degree. His $\mathrm{Ph}$. D. thesis is devoted to the research an development of energy storage in electric vehicle applications. He is currently with the Power Electrical and Electronic Systems (PE\&ES) Research Group (http://peandes.unex.es). His research interests are power electronics in the power system, battery chargers, battery equalization and electric vehicles.

E-mail: jagallardo@peandes.net

Postal address: Universidad de Extremadura, Campus universitario, Escuela de Ingenierías Industriales, Laboratorio C2.7, Avda. de Elvas, s/n 06006, Badajoz, Spain

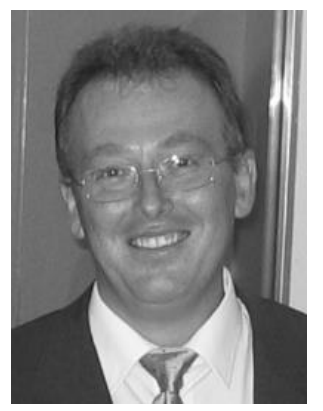

Enrique Romero-Cadaval was born in Villafranca de los Barros, Badajoz, Spain, in 1968. He received the M. Sc. degree in electronic industrial engineering at ICAI, Universidad Pontificia de Comillas, Madrid, Spain, in 1992 and the Ph. D. degree from the Universidad de Extremadura, Badajoz, Spain, in 2004. He is a full Professor in power electronics at the University of Extremadura, Badajoz, Spain. He is currently with the Power Electrical and Electronic Systems (PE\&ES) Research Group (http://peandes.unex.es). His research interests are power electronics in the power system, power quality, electromagnetic interferences, active power filters, electric vehicle and renewable energy sources control.

E-mail: eromero@unex.es

Postal address: Universidad de Extremadura, Campus universitario, Escuela de Ingenierías Industriales, Laboratorio C2.7, Avda. de Elvas, s/n 06006, Badajoz, Spain.

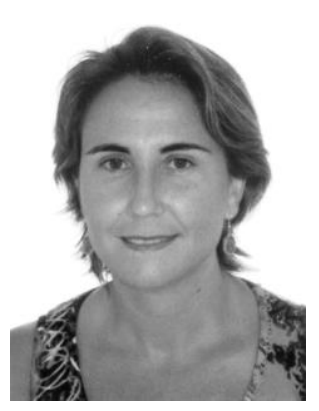

María Isabel Milanés-Montero (S'03M'06) was born in Badajoz, Spain, in 1974. She received the $\mathrm{M}$. Sc. degree in industrial engineering and the $\mathrm{Ph} . \mathrm{D}$. degree at the University of Extremadura, Badajoz, in 1997 and 2005, respectively. Since November 1998, she has been with the University of Extremadura, where she was first an Assistant Professor at the Electrical, Electronics and Automation Engineering Department and is currently at the Power Electrical and Electronic Systems Research Group, School of Industrial Engineering. Her major fields of research interest include solid-state power converter design and control, electromagnetic interferences, power quality, renewable energy sources control, and electrical machine drives

E-mail:milanes@unex.es

Postal address: Universidad de Extremadura, Campus universitario, Escuela de Ingenierías Industriales, Laboratorio C2.7, Avda. de Elvas, s/n 06006, Badajoz, Spain.

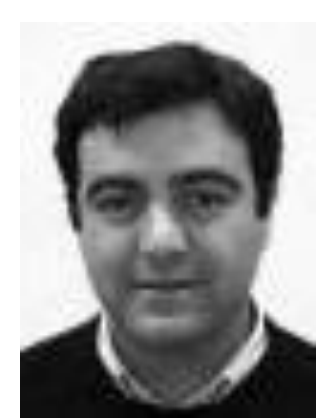

Miguel A. Guerrero-Martinez received the M. Sc. degree in Physics and the M. Sc. degree in Electronic Engineering from the University of Extremadura, Badajoz, Spain, in 2002 and 2006, respectively.

$\mathrm{He}$ is currently working as Technical assistant with the Power Electrical and Electronic Systems Research Group, in the Electric, Electronic and Automatic Engineering Department, in the School of Industrial Engineering, of the University of Extremadura. His research interests include power electronics in the power system, power quality, renewable energy sources control, grid integration of renewable energy systems, and energy-storage applications.

E-mail: mguerrero@peandes.net

Postal address: Universidad de Extremadura, Campus universitario, Escuela de Ingenierías Industriales, Laboratorio C2.7, Avda. de Elvas, s/n 06006, Badajoz, Spain. 